\title{
Celastrol Induces Necroptosis and Ameliorates Inflammation via Targeting Biglycan in Human Gastric Carcinoma
}

\author{
Dandan Guo ${ }^{1}$, Wei Zhang ${ }^{2}$, Haijie Yang ${ }^{3}$, Jiajia Bi ${ }^{1}$, Yunfei Xie ${ }^{3}$, Binfeng Cheng ${ }^{3}$, Yan Wang ${ }^{1}$ \\ and Sujuan Chen ${ }^{1, *}$ \\ 1 Synthetic Biology Engineering Lab of Henan Province, School of Sciences and Techanology, Xinxiang \\ Medical University, Henan 453003, China; 52181300030@stu.ecnu.edu.cn (D.G.); 141005@xxmu.edu.cn (J.B.); \\ 111015@xxmu.edu.cn (Y.W.) \\ 2 College of Animal Science and Veterinary Medicine, Henan Institute of Science and Technology, Xinxiang, \\ Henan 453003, China; xuyanzhao@hist.edu.cn \\ 3 School of Sciences and Technology, Xinxiang Medical University, Henan 453003, China; \\ 131035@xxmu.edu.cn (H.Y.); xieyf@xxmu.edu.cn (Y.X.); chengbinfeng@xxmu.edu.cn (B.C.) \\ * Correspondence: 131016@xxmu.edu.cn
}

Received: 5 July 2019; Accepted: 12 November 2019; Published: 14 November 2019

\begin{abstract}
Celastrol, a triterpene isolated from the root of traditional Chinese medicine Thunder of God Vine, possesses anti-cancer and anti-inflammatory activity to treat rheumatoid disease or as health product. Necroptosis is considered as a new approach to overcome chemotherapeutics resistance. However, whether celastrol exerts necroptosis leading to gastric cancer cell death is still unclear. Here, for the first time we showed that celastrol induced necroptosis in HGC27 and AGS gastric cancer cell lines. More importantly, celastrol down-regulated biglycan (BGN) protein, which is critical for gastric cancer migration and invasion. Furthermore, celastrol activated receptor-interacting protein 1 and 3 (RIP1 and RIP3) and subsequently promoted the translation of mixed-lineage kinase domain-like (MLKL) from cytoplasm to plasma membrane, leading to necroptosis of gastric cancer cell, which was blocked by over-expression BGN. In addition, celastrol suppressed the release of pro-inflammatory cytokines TNF- $\alpha$ and IL-8 in HGC27 and AGS cells, which was reversed by over-expression BGN. Taken together, we identified celastrol as a necroptosis inducer, activated RIP1/RIP3/MLKL pathway and suppressed the level of pro-inflammatory cytokines by down-regulating BGN in HGC-27 and AGS cells, which supported the feasibility of celastrol in gastric cancer therapy.
\end{abstract}

Keywords: celastrol; necroptosis; biglycan; cytokines; gastric cancer cells

\section{Introduction}

Gastric cancer is a common malignant tumor of digestive system worldwide, and its incidence rate is particularly high around the world, especially in eastern Asia [1-3]. Clinical data revealed the detection rate of early gastric cancer is very low, so most patients have reached the advanced stage because of symptoms. Chemotherapy and radiotherapy are common therapeutic strategies [4]. However, the response rate to the chemotherapeutic drugs is only between $20 \%$ and $40 \%$ [5]. Resistance to cell apoptosis is a major obstacle in gastric cancer chemotherapy. Thus, application of anticancer agents targeting non-apoptitic cell death pathways may be a novel anticancer strategy.

In recent years, it has been reported that cell death involves two kinds of mechanisms (caspase-dependent and caspase-independent). Caspase-independent cell death has been named necroptosis, which is also a kind of important programmed cell death [6]. Necrosome, a complex assembled from political signaling molecules mediates the development of necroptosis, 
including caspase-8, Fas-associated death domain protein (FADD), and two receptor-interacting serine/threonine-protein (RIP1 and RIP3). Many stimulis such as TNF- $\alpha$ induce the interaction between RIP1 and RIP3 resulting in the formation of necrosome [7,8]. After that, RIP3 is activated and in turn recruits its downstream protein mixed-lineage kinase domain-like (MLKL). Then, MLKL translocates from cytoplasm to plasma membrane, eventually forming calcium influx-mediated pore to promote necroptosis [9].

Biglycan (BGN), a proteoglycan whose core protein is glycanated by two GAG chains, is a member of the superfamily of proteoglycans called the small leucine repeat proteoglycan family (SLRP) [10]. BGN exists in almost all organs of our body, but its distribution is not uniform, which mainly distributed in the extracellular matrices and on the cell surface of some specialized cells $[6,11-13]$. The functions of BGN are dependent on the microenvironment in which it acts as a structural molecule or signaling molecule $[14,15]$. Therefore, it is not surprising that biglycan possesses a variety of functions involving in atherosclerotic plaques, long-term memory, bone mass and cell migration [16]. Recent studies have indicated significantly higher expression of BGN in tumor tissues compared with adjacent normal tissues, including colon tumor, ovary cancer, pancreatic adenocarcinoma, intrahepatic cholangiocarcinoma, and gastric cancer [17-21]. Abnormal BGN expression in tumor tissues suggests that it plays an oncogenic role in cancer migration and invasion [22,23].

There is mounting evidence that BGN not only directly triggers pro-inflammatory TLR- and inflammasomes-signaling but also stimulates the generation of pro-inflammatory cytokines (eg. TNF- $\alpha$, IL-1 $\beta$, IL-6 and IL-8) and ROS, which are crucial mediators of inflammation and angiogenesis in cancer development [24]. It is conceivable that the regulation of BGN in cancer is closely associated with inflammation. Large amounts of cytokines, chemokines, and ROS contributed to tumor initiation and progression. Moreover, the inflammasome as key signal in microenvironment is the hallmark in each stage of tumor development $[25,26]$. Despite emerging insight that BGN may affect cancer development dependent on inflammation, the relation between BGN and necroptosis in gastric cancer remains to be uncovered.

Celastrol, extracted from the root of the plant Tripterygium wilfordii (Thunder of God vine), is one of the quinone methide triterpenoids $[27,28]$, which is used in traditional Chinese medicine and health products as food compound [29,30]. It is well-known that celastrol have exhibited diverse pharmacological properties for therapeutic potential, including anti-rheumatoid arthritis, antioxidant, and anti-cancer effects [31-35]. Recently, celastrol has also been found to inhibit gastric cancer growth by induction of apoptosis and autophagy. However, it is unknown whether necroptosis is involved in the molecular mechanism of celastrol-induced gastric cancer cell death.

In this study, for the first time, our results indicate the celastrol induced necroptosis and attenuated the release of pro-inflammatory cytokines via down-regulating BGN level in the gastric carcinoma cell lines HGC-27 and AGS cells. Furthermore, celastrol activated RIP1/RIP3/MLKL signaling pathway, leading to necroptosis.

\section{Results}

\subsection{Celastrol Induces Gastric Cancer Cell Death, Possibly via Necroptosis}

Recently, it was reported that natural compounds such as matrine [36], tanshinone IIA [37], shikonin [38], induced cancer cell death by necroptosis. Celastrol inhibited the growth of gastric cancer cells [39], however, whether necroptosis participated in the event of celastrol-induced cell death is unknown. To investigate whether celastrol induces necroptosis in gastric cancer cells, we first tested the cytotoxicity of celastrol in cell lines (HGC-27, AGS) and human normal gastric epithelial cell line GES-1 cells. Results from MTT assay showed that celastrol inhibited proliferation in a dose-dependent manner in two cells lines tested. However, celastrol $(0-1 \mu \mathrm{M})$ had no effect on the survival of GES- 1 cells. About $60.0 \%$ suppression rate of cell growth was produced after treatment with $0.5 \mu \mathrm{M}$ celastrol for $24 \mathrm{~h}$ 
(Figure 1A). We further explored necroptosis by PI staining and Western blotting assay. Flow cytometry analysis indicated that celastrol induced cell death in a concentration-dependent manner (Figure 1B,C).
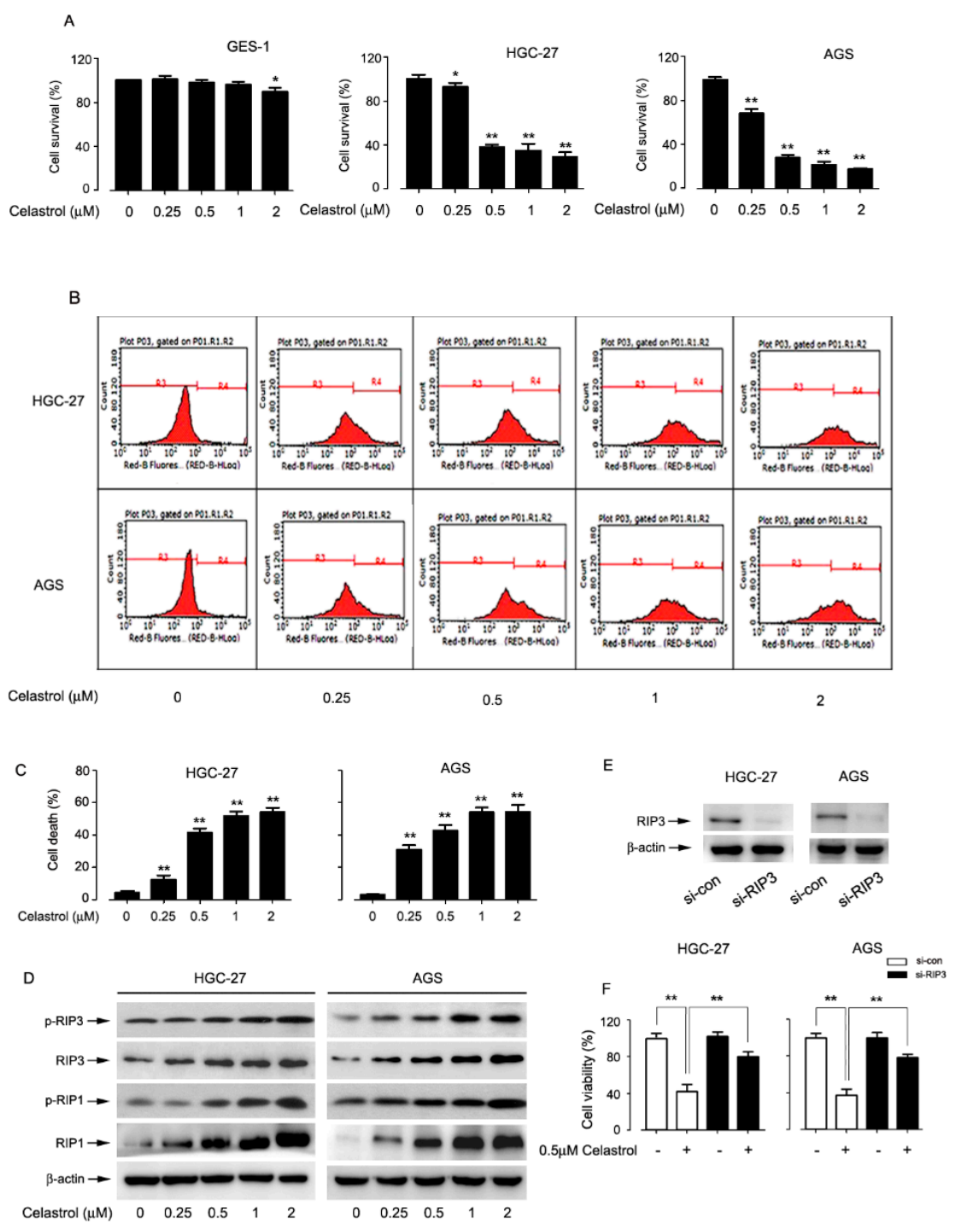

G

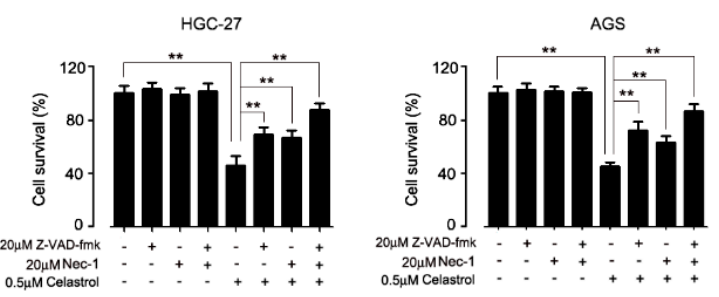

Figure 1. Celastrol partially induced necroptosis in gastric cancer cells. HGC-27, AGS and GES-1 cells were treated with different concentrations $(0,0.25,0.5,1$, and $2 \mu \mathrm{M})$ of celastrol for $24 \mathrm{~h}$. 
After that, (A) the percentage of cell survival was determined with MTT assay and (B and C) the percentage of cell death was determined with PI staining plus flow cytometry. All data were presented as the mean \pm S.D. of at least three independent experiments. Significant differences compared with controls were indicated as ${ }^{*} P<0.05$ and ${ }^{* *} P<0.01$. (D) The expression of $\mathrm{p}$-RIP1 and p-RIP3 were detected by Western blot analysis. $\beta$-actin was used as an internal control. (E) Cells were transfected with scrambled siRNA (con) or siRIP3 for $72 \mathrm{~h}$ prior to celastrol $(0.5 \mu \mathrm{M})$ treatment for $24 \mathrm{~h}$. The efficiency of siRIP3 in HGC-27 and AGS cells were determined by Western blot. (F) The MTT assay showed that RIP3 silencing significantly rescued celastrol-induced cell death in HGC-27 and AGS cells. (G) Cells were pretreated with/without $20 \mu \mathrm{M}$ Z-VAD-fmk or $20 \mu \mathrm{M} \mathrm{Nec}-1$ following by $0.5 \mu \mathrm{M}$ celastrol for $24 \mathrm{~h}$. After that, the percentage of cell survival was determined with MTT assay. Values were presented as mean $\pm \mathrm{SD}$ of three determinations obtained from three different experiments, ${ }^{*} P<0.05,{ }^{* *} P<0.01$.

The expression of RIP1 and RIP3 is essential for the formation of necrosome to undergo necroptosis. Therefore, we investigated the change of RIP1 and RIP3 level in HGC-27 and AGS cells after exposed celastrol. Results from Western blotting showed that celastrol dramatically activated p-RIP1 and p-RIP3 of two cells lines tested in a dose-dependent manner (Figure 1D). To further clarify the role of necroptosis in celastrol-induced gastric cancer cell death, we used siRNA technology to interfere with RIP3 expression. As the results showed in Figure 1E,F, knockdown RIP3 significantly inhibited celastrol-induced cell death in gastric cancer cell. We also evaluated the role of apoptosis and necroptosis on celastrol-triggered cell death. From the result of Figure 1G, both apoptosis inhibitor (Z-VAD-fmk) and RIP1 inhibitor (Nec-1) in part rescued celastrol-triggered gastric cancer cell death. The combination of them had induced stronger protective effect on the cytotoxicity of celastrol in gastric cancer cell than Z-VAD-fmk + celastrol group or Nec-1 + celastrol group separately. The above data indicate that celastrol partially induces necroptosis in gastric cancer cell lines.

\subsection{Celastrol Down-Regulated the Expression of BGN Leading to HGC-27 and AGS Cell Death}

BGN expression was upregulated in gastric cancer tissues to enhance gastric cancer invasion [6]. We therefore hypothesized that celastrol-induced cell death is closely related with BGN. The results showed that celastrol remarkably down-regulated the BGN protein level in HGC-27 and AGS cells (Figure 2A). To dissect the role of BGN in celastrol-induced cell death, endogenous BGN in HGC-27 and AGS cells was over-expressed using lentivral-mediated technology (Figure 2B). Interestingly, we found that over-expression of BGN dramatically attenuated celastrol-induced cell death (Figure 2C). In addition, by phase-contrast microscopic observation, morphological changes of HGC-27 and AGS cells, because of treatment to celastrol, included rounding and shrinkage, which was markedly abolished by over-expression of BGN (Figure 2D). To further clarify the relationship between BGN and celastrol in gastric cancer cell, BGN gene was silenced using siRNA technique. As illustrated in S1, BGN expression was remarkably knocked down in BGN-specific siRNA-transfected cells, compared with scrambled siRNA-transfected control cells (Figure A1A). MTT assay demonstrated that BGN silencing decreases the cell viability in the presence of celastrol in HGC-27 and AGS cells (Figure A1B). These results indicate that the cell death induced by celastrol in gastric cells targets BGN. 


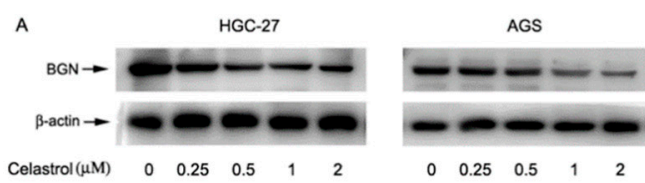

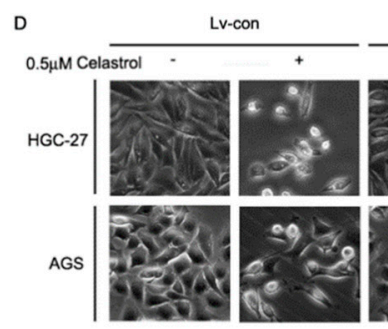

HGC-27

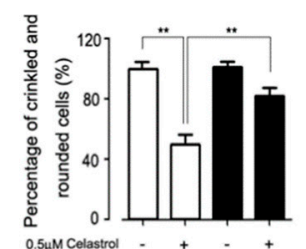

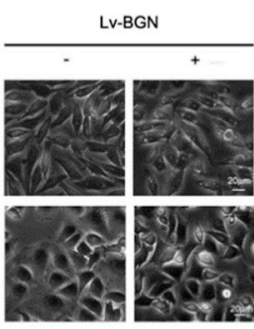

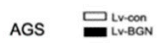

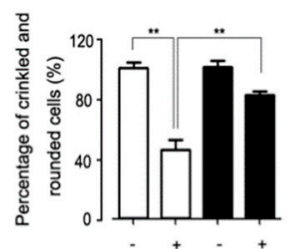

Figure 2. BGN down-regulated by celastrol is associated with cell death in gastric cancer cells. (A) Celastrol inhibited the expression of BGN in a dose dependent manne in HGC-27 and AGS cells. Cells were treated with different concentration $(0,0.25,0.5,1$, and $2 \mu \mathrm{M})$ celastrol for $24 \mathrm{~h}$, and BGN was detected by Western blot. (B) The efficiency of over-expression BGN in HGC-27 and AGS cells was determined by Western blot. (C and D) HGC-27 and AGS cells were infected by lentiviral vector for over-expression of BGN or GFP and then treated with $0.5 \mu \mathrm{M}$ celastrol for $24 \mathrm{~h}$. The percentage of cell survival was estimated by MTT assay (C), and the morphology of cells was assessed using an Olympus inverted phasecontrast microscope $(200 \times)$ equipped with Quick Imaging system. Scale bar: $20 \mu \mathrm{m}$. Results are presented as mean $\pm \mathrm{SE}, n=6-12 .{ }^{*} P<0.05,{ }^{* *} P<0.01$ (D).

2.3. Celastrol Down-Regulated the Expression of BGN to Activate RIP1/RIP3 Necroptosis Signaling in HGC-27 and AGS Cells

To further test whether BGN participated in celastrol-induced necroptosis in gastric cancer, we evaluated the necroptosis by flow cytometry and Western blotting. Results showed that over-expression of BGN obviously inhibited celastrol-induced increase of necroptosis in both HGC-27 and AGS cell lines (Figure 3A). Further study with Western blotting analysis showed that BGN overexpression exhibited the effect of inhibiting celastrol-induced phosphorylation of RIP1 and RIP3 in two cells lines tested (Figure 3B,C). These data indicate that celastrol targets down-regulating BGN and then promotes RIP1/RIP3 expression, resulting in the necroptosis. 


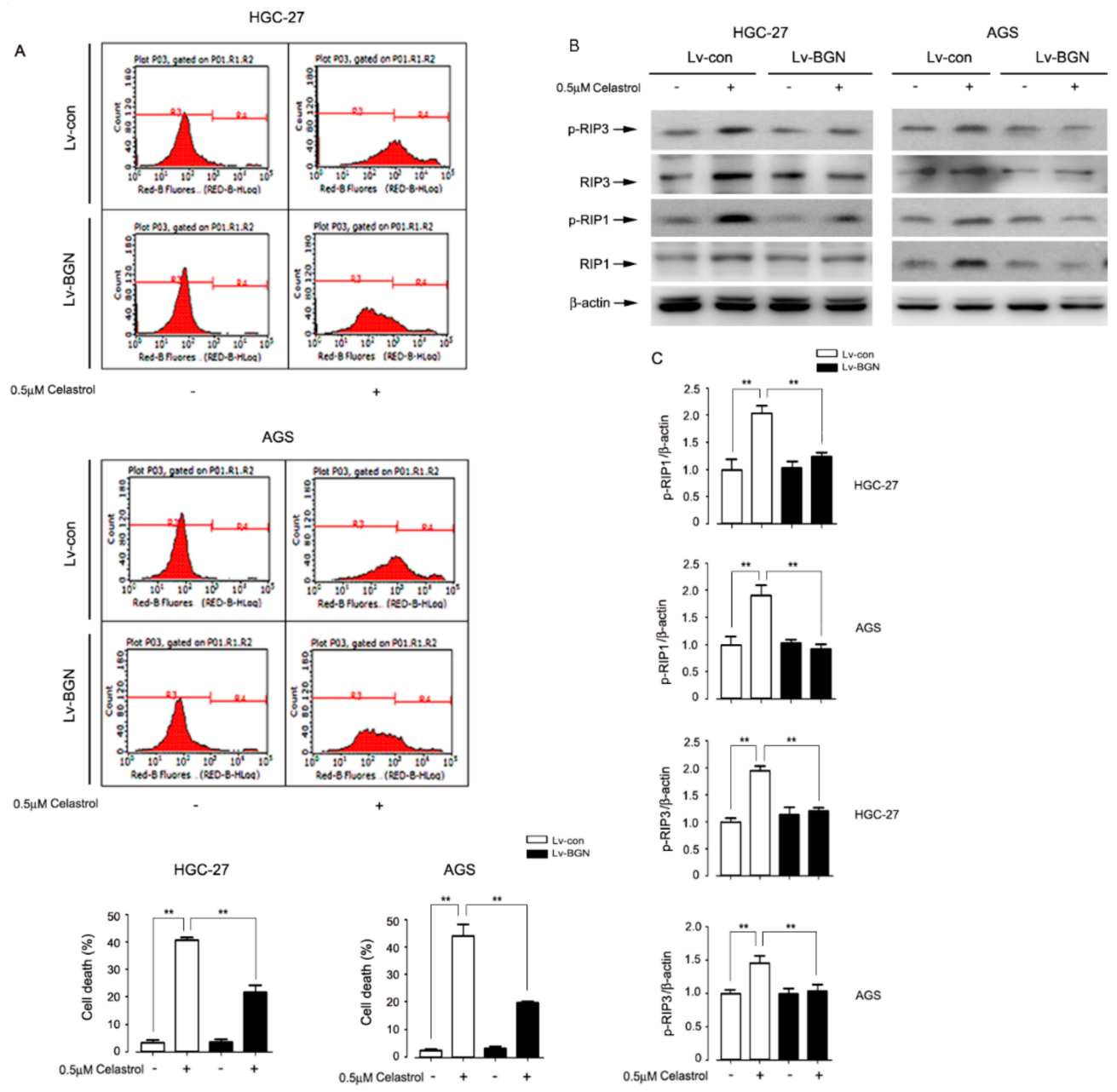

Figure 3. BGN down-regulated by celastrol is associated with necroptosis by regulating RIP1 and RIP3 in gastric cancer cells. BGN in HGC-27 and AGS cells was over-expressed with lentiviral vector, and then cells were treated with $0.5 \mu \mathrm{M}$ celastrol for $24 \mathrm{~h}$. The percentage of cell death was estimated by PI staining plus flow cytometry (A) and the expression of p-RIP1 and p-RIP3 was detected by Western blotting (B). The blots for p-RIP1 and p-RIP3 were semi-quantified using NIH image J (C). Results were presented as the mean \pm S.D. of at least three independent experiments. Significant differences compared with controls were indicated as ${ }^{*} P<0.05$ and ${ }^{* *} P<0.01$. $\beta$-ac tin was used as an internal control.

\subsection{Celastrol Promoted the Translation of MLKL, Leading to Necroptosis in HGC-27 and AGS Cells}

MLKL is the critical substrate of RIP3 in necroptosis signaling pathway. To confirm the finding that celastrol induced necroptosis, we tested whether MLKL participated in the event. As the results from Western blotting showed that celastrol induced the phosphorylation of MLKL, which was signficantly attenuated by BGN overexpression in HGC-27 and AGS cells (Figure 4A). Translocation of MLKL from cytoplasm to plasma membrane leading to fatal permeabilization of the plasma is required for necroptosis. The result from immunofluorescent staining showed that MLKL was originally located in the cytoplasm of control cells. However, most of MLKL moved to the plasma membrane after celastrol treatment, which was obviously prevented by over-expression of BGN (Figure 4B). Furthermore, the result showed that cell death caused by celastrol was significantly suppressed by MLKL-specific inhibitor necrosulphonamide (NSA) in HGC-27 and AGS cells (Figure 4C). These data together indicate that celastrol down-regulates the expression of BGN to activate RIP3/MLKL signaling, leading to necroptosis in HGC-27 and AGS cells. 


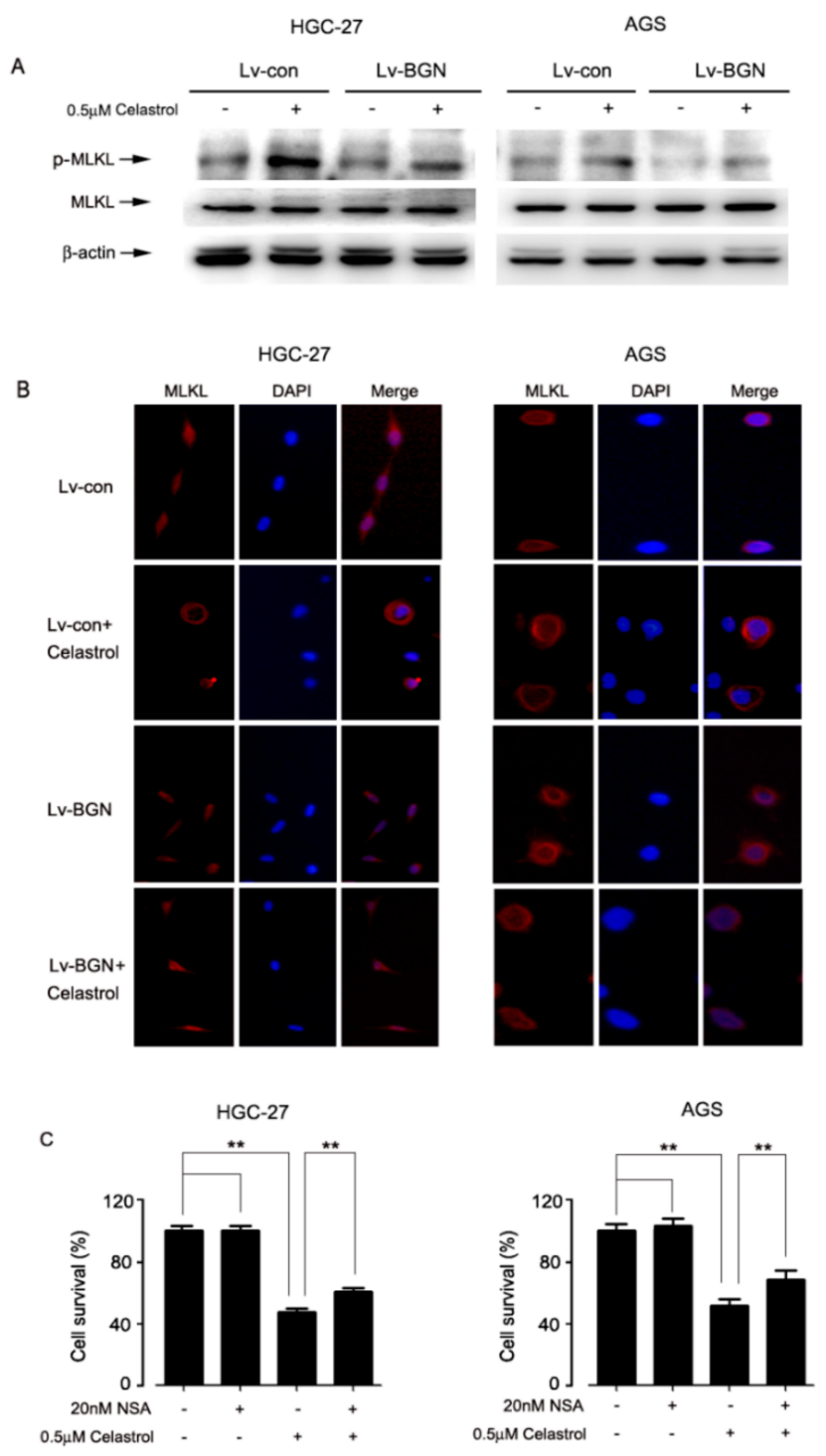

Figure 4. MLKL as a downstream of BGN/RIP3 is requred for celastrol inducing necroptosis. (A) Over-expression BGN protein blocked celastrol-induced the phosphorylation of MLKL and (B) the translocation from cytoplasm to plasma membrane. Subcellular localization of MLKL was analyzed by immunofluorescence and fluorescent light microscope. (C) Cells were pre-treated with MLKL inhibitor NSA $(20 \mathrm{nM})$ for $2 \mathrm{~h}$ and then treated with $0.5 \mu \mathrm{M}$ celastrol for $24 \mathrm{~h}$. After then, the percentage of cell survival was estimated by MTT assay.

2.5. Inhibition of Necroptosis by Nec-1 Attenuated Celastrol-Induced Cell Death in Part by Up-Regulating the Expression of BGN in HGC-27 and AGS cells

To further investigate the relationship between celastrol-mediated BGN expression and necroptosis, cells were incubated with RIP1 inhibitor necrostatin-1 (Nec-1) for $2 \mathrm{~h}$ before treatment by celastrol. The MTT result showed that celastrol-induced cell death was significantly blocked by Nec-1; Nec-1 and over-expression BGN had a stronger interference effect on celastrol-induced cell death than alone over-expression BGN or Nec-1 (Figure 5A). In addition, Western blotting showed that Nec-1 markedly inhibited the celastrol-activated p-RIP1and p-RIP3. Interestingly, inhibition necroptosis by Nec-1 up-regulated BGN level in cells exposed to celastrol, signaling a feed-forward regulation of BGN by RIP1 (Figure 5B). The data indicate that celastrol induced cell death in HGC-27 and AGS cells at least in part through BGN-activating necroptosis. 


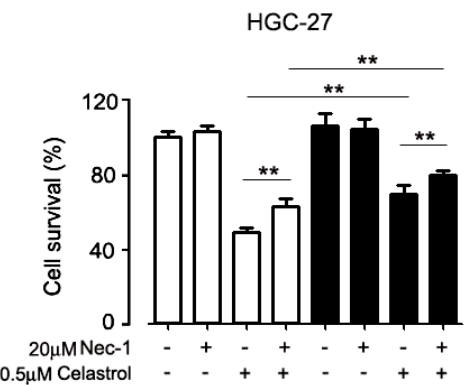

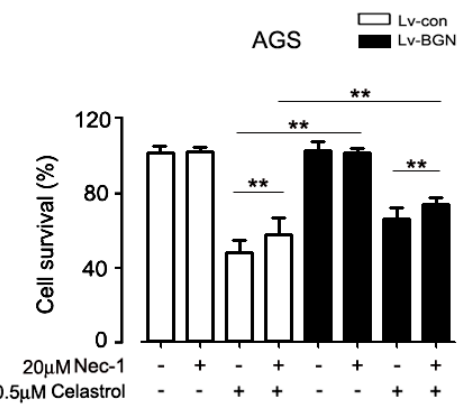

$0.5 \mu \mathrm{M}$ Celastro

B
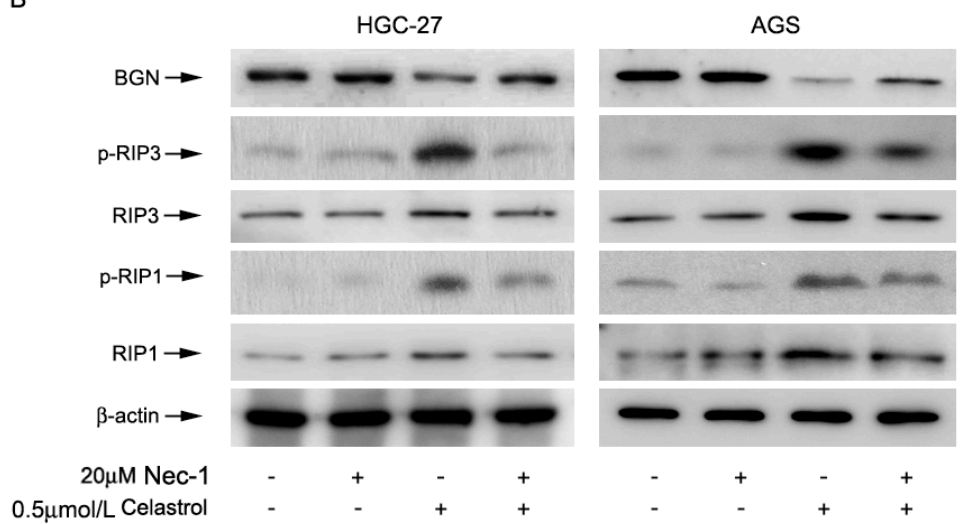

Figure 5. Inhibition of necroptosis by Nec-1 attenuated celastrol-induced cell death in HGC-27 and AGS cells. (A) Cells expressing control or over-expressing BGN were pre-treated with necroptosis inhibitor Nec-1 $(20 \mu \mathrm{M})$ for $2 \mathrm{~h}$ and then treated with $0.5 \mu \mathrm{M}$ celastrol for $24 \mathrm{~h}$. After then, (A) the percentage of cell survival was estimated by MTT assay, and (B) the expression of p-RIP1, p-RIP3, and BGN was determined by Western blot analysis. Results were presented as the mean \pm S.D. of at least three independent experiments. Significant differences compared with controls were indicated as ${ }^{*} P<0.05$ and ${ }^{* *} P<0.01$.

2.6. Celastrol Blocking BGN Was Accompanied by Suppressing Pro-Inflammatory Cytokine Production in HGC-27 and AGS Cells

We then sought to investigate whether celastrol mediated inflammation by targeting BGN in gastric cancer cells; we evaluated the secretion of pro-inflammatory cytokine TNF- $\alpha$ and IL-8. High inflammation always existed in cancer cells. As shown by the data (Figure 6A,B), we found that there was a certain expression of TNF- $\alpha$ and IL-8 in untreated HGC-27 and AGS cells. Celastrol treatment partially inhibited their production in gastric cells and overexpression of BGN restored the level of TNF- $\alpha$ and IL-8 compared to celastrol group. Similar results were shown in HGC-27 and AGS cells. These data suggest that celastrol inhibits the expression of BGN, contributing to attenuate inflammation in gastric cancer cells. 
A

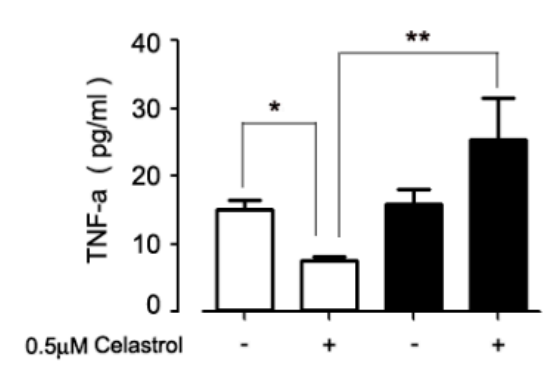

B

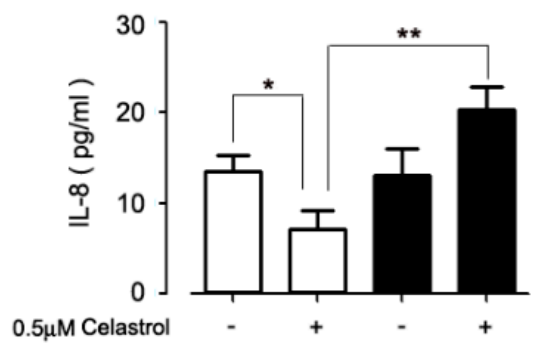

HGC-27

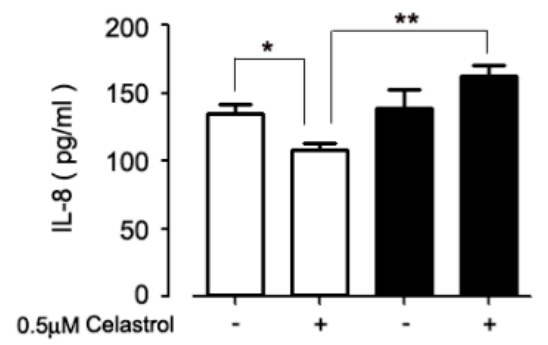

Figure 6. BGN up-regulated celastrol-attenuated inflammatory markers in HGC-27 and AGS cells. Cells expressing control (LV-con) or over-expressing BGN (LV-BGN) were treated with or without $0.5 \mu \mathrm{M}$ celastrol for $24 \mathrm{~h}$. After then, TNF- $\alpha$ (A) and IL-8 (B) secretion was determined using ELISA method. Data are the mean \pm SD of three independent experiments. Significant differences compared with controls were indicated as ${ }^{*} P<0.05$ and ${ }^{* *} P<0.01$.

\section{Discussion}

In the present study, we have found a novel role of celastrol as an anti-tumor medicine through reducing the expression of BGN to activate RIP1/RIP3/MLKL signaling pathway, leading to necroptosis and decreased secretion of pro-inflammatory cytokines in HGC-27 and AGS cells (Figure 7). Celastrol-induced necroptosis was confirmed by necrosis-related protein RIP1 and RIP3, and the rescue effects of necroptosis inhibitor Nec-1 and NSA. High expression of BGN was existed in gastric cancer cells, which was down-regulated by celastrol in a dose dependent manner. On the basis of the key role of RIP1/RIP3/MLKL signaling in necroposis [8,40], we proved that celastrol promoted the phosphorylation of RIP1 and RIP3 and plasma membrane translocation of MLKL in HGC-27 and AGS cells, which was prevented by BGN over-expression. Moreover, further results showed that necroptosis inhibitor Nec-1 attenuated the inhibition effect of celastrol on BGN. In addition, celastrol inhibited the production of pro-inflammatory cytokines in HGC-27 and AGS cells by blocking BGN. This study unveils the mechanism of celastrol-induced gastric cancer cell death and underscores the importance of BGN-mediated necroptosis and inflammation in celastrol-induced cell death.

Most patients diagnosed with advanced gastric cancer receive chemotherapeutic treatment [41]. However, the high rate of adverse effects and rapid therapeutic resistance of chemotherapy to limit to treatment is not ginored. Recent studies have shown that chemotherapy normally killed RIP3 and MLKL-deficient tumor cells resulting in apoptosis by activating caspase- 3 and yet was unable to reduce their growth in vivo. Interesting, up-regulation of RIP3 alleviated cervical cancer progression and promoted cell's sensitivity to chemotherapy [42]. Once knockdown of RIP3, the effect of TNF- $\alpha$ strengthening the cytotoxicity of 5-FU in breast cancer cells was abolished [43,44]. Our present study indicated that RIP1/RIP3 was expressed at low levels in two kinds of gastric cancer cells, and celastrol greatly enhanced the expression of RIP1/RIP3 leading to necroptosis, which contributed to gastric cancer cell death. We have no idea whether celastrol promotes the cell's sensitivity to chemotherapy 
and radiotherapy against gastric cancer cells. Of course, further studies still are needed to address this issue.

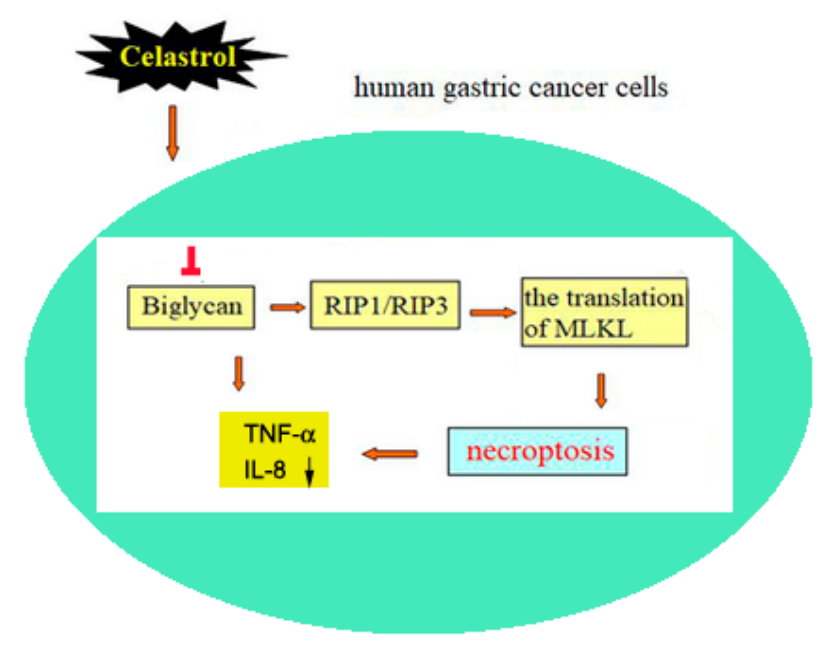

Figure 7. Summary of possibly involved mechanism in anti-tumor effect of celastrol on human gastric cancer cells. Celastrol targeting on inhibiting the expression of BGN significantly promotes the expression of RIP1 and RIP3 and the translation of MLKL from cytoplasm to plasma membrane, leading to the decrease of pro-inflammation cytokines's production in human HGC-27 and AGScells.

Particularly noteworthy, more and more natural compounds derived from plants or microbes have exhibited promising therapeutic effects for cancer [36-38,45]. Celastrol has shown the capacity of inhibiting gastric cancer cells by inducing apoptosis. In our study, surprisingly, we found celastrol induced necroptosis in gastric cancer cells. Our results are in line with the recent Lin's studies on tanshinone IIA simultaneous induction of apoptosis and necroptosis in human hepatocellular carcinoma HepG2 cells. It is generally believed that necroptosis is incompatible with apoptosis. For example, matrine [36], shikoni [38], and neoalbaconol [45] individually induced necroptosis but not apoptosis in some cancer cell lines. In this study, we noticed that necroptosis inhibitor Nec-1 and NSA in part attenuated celastrol-triggered cell death in HGC-27 and AGS cells, which suggest that expecting apoptosis, celastrol has anticancer ability by inducing necroptosis in gastric cancer cells.

To date, a novel function of biglycan as a signaling molecule and a crucial pro-inflammatory factor has long been appreciated [24,46]. Recently, several research groups have found abnormal expression of BGN in tumors, which is closely related to the migration and poor prognosis of tumors, including gastric cancer [17-21]. The data suggest that higher expression of BGN plays an oncogenic role in cancer migration and invasion [22,23]. Growing evidences have shown that BGN as a danger signal has the pro-inflammatory effect. Mechanistically, it activates some signaling pathway such as Erk, p38, NF-kB by engaging TLR2/4, leading to the synthesis and secretion of pro-inflammatory cytokines and chemokines, such as IL-1, TNF- $\alpha$. In addition, it was reported that biglycan-deficient mice show improved survival in LPS-induced sepsis and less severe inflammation in both models of sterile inflammatory renal injury and LPS-induced sepsis because of decreased levels of active caspase-1 and mature IL-1 [24,47-49]. According to our current knowledge, biglycan-mediated inflammatory milieu may promote tumor growth. On a positive note, for the first time, we found that celastrol inhibited the expression of BGN, and over-expression of BGN prevented celastrol-induced necroptosis in gastric cancer cells. These data indicate that BGN is an important target of celastrol in cancer, and its regulation of necroptosis may be a promising therapeutic strategy for the prevention and treatment of gastric cancer. In regards to the role of proteoglycans in the regulation of necroptosis, it has not been previously documented. Of course, the exact mechanism still needs to be further studied.

A recent study has demonstrated that necroptosis might have anti-inflammatory effects in certain settings, through curbing excessive TNF- $\alpha$ or TLR-induced inflammatory cytokine production. 
Once the necroptosis effectors, RIPK1 and RIPK3 were blocked, the production of pro-inflammatory cytokine was triggered. In other words, diminished necroptosis can lead to enhanced inflammatory responses [50-52]. In our study, we found that celastrol had the ability of anti-inflammatory effects via inhibiting BGN in gastric cancer (Figure 6). Other studies have indicated that celastrol inhibited gastric cancer growth in vivo by induction of apoptosis and autophagy [39]. To further verify the necroptosis of celastrol, we will conduct experiments at the animal level. This will provide a theoretical basis for the promotion of celastrol. Based on above two points, we speculate that the inhibitory effect of celastrol on pro-inflammatory cytokine is attributed to the downregulation of BGN and the activation of necroptosis. These findings support the potential use of celastrol as an effective therapeutic agent for gastric cancer patients.

\section{Materials and Methods}

The primary antibodies against RIP1 (Ser166), RIP1, RIP3, and $\beta$-actin were from Cell Signaling Technology (Danvers, MA, USA). Anti-BGN and anti-MLKL antibodies were obtained from Sigma (St Louis, MO, USA). Anti-RIP3 (Ser227) and anti-MLKL (Ser358) antibodies were purchased from Abcam company (Cambridge, MA). Roswell Park Memorial Institute (RPMI)-1640 medium was supplied by Thermo Fisher Scientific, Inc (Logan, UT, USA). Celastrol, Dimethyl sulfoxide (DMSO), cell lysates, 4\% paraformaldehyde and 3-(4, 5-dimethylthiazol-2-yl)-2, 5-diphenyltetrazolium bromide (MTT) were purchased from Sigma, whereas 0.05\% Trypsin-EDTA and Fetal bovine serum (FBS) were from Invitrogen (Grand Island, NY, USA). Inhibitors Z-VAD-fmk, necrostatin-1 (Nec-1) and necrosulphonamide (NSA) were purchased from TRC (Toronto, Ontario, Canada). Enhanced chemiluminescence solution was purchased from Pierce (Rockford, IL, USA).

\subsection{Cell Culture}

Two human gastric cancer cell lines (human gastric carcinoma HGC-27 cell lines; human gastric adenocarcinoma AGS cell lines) were obtained from American Type Culture Collection (Manassas, VA, USA) and normal gastric epithelial cell lines (GES-1) were purchased from Shanghai cell bank. Cells were grown in RPMI-1640 medium supplemented with $10 \%$ FBS, $1 \%$ penicillin, and streptomycin. Cells were maintained at $37^{\circ} \mathrm{C}$ in a humid incubator $\left(37^{\circ} \mathrm{C}, 5 \% \mathrm{CO}_{2}\right)$.

\subsection{Western Blot Analysis}

The cell cultures were harvested and lysed in lysis buffer on ice for $20 \mathrm{~min}$. Determination of protein concentrations were conducted as Bradford's method. Followed by equivalent amounts of protein boiled for 5 min with sample buffer and cooled on ice, proteins were separated on concentration-appropriate gels by SDS-PAGE and electrophoretically transferred to polyvinylidene diflouride filter (PVDF) membranes (Millipore, Bed ford, MA, USA). After being blocked with 5\% non-fat dry milk in TBST for $1 \mathrm{~h}$ at room temperature, the membranes were incubated with primary antibodies against $\beta$-actin, BGN, RIP1, RIP3, and p-MLKL at $4{ }^{\circ} \mathrm{C}$ overnight, subsequently with appropriate secondary antibodies conjugated to horseradish peroxidase (HRP) for $35 \mathrm{~min}$ at room temperature. Finally, proteins were detected by an enhanced chemiluminescence solution (Pierce) and analyzed. $\beta$-actin was used as a loading control. NIH image J was used to analysis the histogram.

\subsection{Cell Viability Assay}

The AGS and HGC cells were respectively seeded in a flat-bottomed ninety-six-well plate at a density of $1 \times 10^{5}$ cells $/ \mathrm{mL}$. The cells were treated with different concentrations of celastrol for $24 \mathrm{~h}$ or with/without $0.5 \mu \mathrm{M}$ celastrol for $24 \mathrm{~h}$ following pre-incubation with/without with Nec-1or NSA for $2 \mathrm{~h}$. After incubation, each well was added $10 \mu \mathrm{L}$ MTT solution $(5 \mathrm{mg} / \mathrm{mL})$ for $4 \mathrm{~h}$ at $37^{\circ} \mathrm{C}$ in a $5 \%$ $\mathrm{CO}_{2}$ incubator and then added $150 \mu \mathrm{L}$ DMSO/well to dissolve formazan crystals. The analysis of cell viability was performed using a microplate reader (Molecular Devices, San Jose, CA, USA) at OD $570 \mathrm{~nm}$. 


\subsection{Cell Morphological Analysis}

Cells were seeded at a density of $1 \times 10^{6}$ cells/well in a six-well plate. Next day, $0.5 \mu \mathrm{M}$ celastrol was added. After $24 \mathrm{~h}$, images were taken with an Olympus inverted phase-contrast microscope (Olympus Optical Co., Melville, NY, USA) (200×) equipped with the Quick Imaging system.

\subsection{Analysis of Cell Death by Flow Cytometry}

Cell death was determined using PI exclusion assay. In brief, after treatment, the cells were digested using trypsin without EDTA. Then the cells were repeatedly washed with cold PBS for three times and centrifuged at $1000 \mathrm{rpm}$ for $5 \mathrm{~min}$. Finally, cells were re-suspended and probed by $5 \mu \mathrm{g} / \mathrm{mL}$ PI for $5 \mathrm{~min}$ at $4{ }^{\circ} \mathrm{C}$ in the dark. Subsequently, the cells undergoing death were immediately analyzed by Guava EasyCyte HT Sampling Flow Cytometer (Merck, Millipore) with an emission wavelength at $630 \mathrm{~nm}$.

\subsection{Immunofluorescence Assay}

The cells were plated in twelve-well plate containing a glass coverslip per well. After $0.5 \mu \mathrm{M}$ celastrol treatment for $24 \mathrm{~h}$, the cells were washed with PBS three times followed by fixed with $4 \%$ paraformaldehyde for $20 \mathrm{~min}$ at room temperature. Subsequently, the fixed cells were permeabilized in $0.5 \%$ Triton X-100 for $20 \mathrm{~min}$. The cells were blocked with 5\% BSA in PBS for $30 \mathrm{~min}$ and washed three times with PBS, followed by staining with anti-MLKL antibody (rabbit, 1:100, Abcam, Cambridge, MA, USA) overnight at $4{ }^{\circ} \mathrm{C}$, and then the FITC-labeled anti-rabbit second antibody (1:200, Santa Cruz Biotech, Santa Cruz, CA, USA) incubation for $1 \mathrm{~h}$ in the dark was performed. Finally, the cells were probed in anti-fade reagent with DAPI for another $10 \mathrm{~min}$. The cells were rinsed and mounted onto slides and then analyzed and imaged by a Carl Zeiss fluorescent light microscope (Thornwood, NY, USA) using a magnification of $10 \times 20$ and resolution of $1200 \times 1200$. Images were acquired with $150 \mathrm{~ms}$ exposure times and were taken with up to 20 images per sequence. Red fluorescence represents MLKL protein, and blue fluorescence represents nucleus.

\subsection{Cytokine Evaluation}

The cells were seeded in six-well plate at the density of $1 \times 10^{5}$ per well overnight and then treated with $0.5 \mu \mathrm{M}$ celastrol for $24 \mathrm{~h}$. Levels of TNF- $\alpha$ and IL-8 in the treated cells were determined using a commercial ELISA kit (KeyGen BioTech, Nanjing, China) according to the manufacturer's instructions.

\subsection{Lentivirus Production and Transfection}

Lentiviral vector encoding biglycan core protein and green fluorescence protein (GFP) (as control) were purchased from Shanghai Sangon Biotech. For use, monolayer cells grown to about $30 \%$ to $50 \%$ confluency were infected with lentivirus-containing supernatant for $72 \mathrm{~h}$. Lentiviral vector transfection was performed as described [53].

\section{9. siRNA Transfection}

Human BGN siRNAs, RIP3 siRNAs and non-targeting control siRNA were purchased from Shanghai GenePharma. siRNA transfection was performed as described [53].

\subsection{Statistical Analysis}

All values were represented as mean \pm S.D. from triplicate independent experiments per condition. One-way ANOVA test (SPSS 19.0 software, IBM Corporation, Armonk, NY, USA) was applied to analyze the differences between groups. ${ }^{*} P<0.05$ and ${ }^{* *} P<0.01$ were accepted to indicate statistically significant differences. 


\section{Conclusions}

In conclusion, our study for the first time found that celastrol could decrease the expression of BGN to induce necroptosis and ameliorate inflammation in gastric cancer cells (Figure 7). As a safe clinical drug, celastrol may act as a potential effective drug to treat gastric cancer.

Author Contributions: D.G. and S.C. planned the study. D.G. conducted the experiments and data analyses. W.Z., H.Y., Y.X., and B.C. technically supported the study. D.G., S.C., J.B., and Y.W. interpreted the data and jointly drafted the manuscript. All authors reviewed and approved the final manuscript.

Funding: The work was supported by the Natural Science Foundation of China (31401181, 81771336, U1704186); Scientific and Technological Research Project of Henan Province (182102311136, 182102311134).

Conflicts of Interest: The authors declare no conflict of interest associated with the work described.

\section{Abbreviations}

$\begin{array}{ll}\text { BGN } & \text { biglycan } \\ \text { FADD } & \text { Fas-associated death domain protein } \\ \text { MLKL } & \text { mixed-lineage kinase domain-like } \\ \text { Nec-1 } & \text { necrostatin-1 } \\ \text { NSA } & \text { necrosulphonamide } \\ \text { SLRP } & \text { small leucine repeat proteoglycan family } \\ \text { RIP1 and RIP3 } & \text { receptor-interacting protein 1 and 3 }\end{array}$

\section{Appendix A}

A

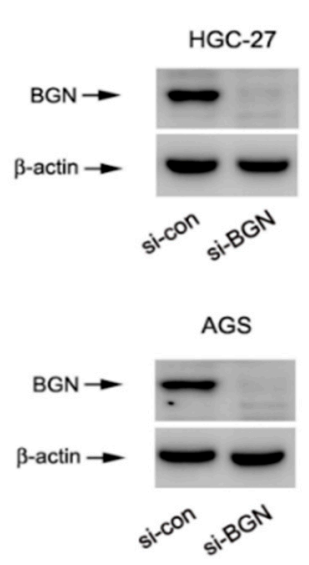

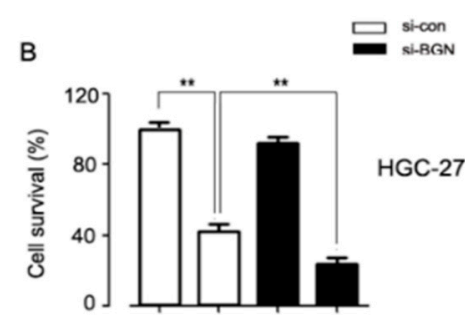

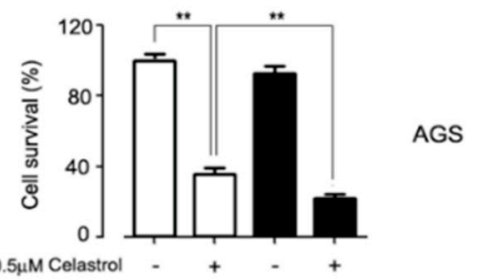

Figure A1. BGN silencing aggravates celastrol-induced cell death in gastric cancer cells. (A) Cells were transfected with scrambled siRNA (con) or siBGN for $72 \mathrm{~h}$ prior to celastrol $(0.5 \mu \mathrm{M})$ treatment for $24 \mathrm{~h}$. The efficiency of siBGN in HGC-27 and AGS cells was determined by Western blotting. (B) The MTT assay showed that BGN silencing enhanced celastrol-induced cytotoxicity in HGC-27 and AGS cells. Values were presented as mean $\pm \mathrm{SD}$ of three determinations obtained from three different experiments, ${ }^{*} P<0.05,{ }^{* *} P<0.01$.

\section{References}

1. Cervantes, A.; Rosello, S.; Roda, D.; Rodriguez-Braun, E. The treatment of advanced gastric cancer: Current strategies and future perspectives. Ann. Oncol. 2008, 19, v103-v107. [CrossRef] [PubMed]

2. Jiang, Y.; Ajani, J.A. Multidisciplinary management of gastric cancer. Curr. Opin. Gastroenterol. 2010, 26, 640-646. [CrossRef] [PubMed]

3. Rivera, F.; Vega-Villegas, M.E.; Lopez-Brea, M.F. Chemotherapy of advanced gastric cancer. Cancer Treat. Rev. 2007, 33, 315-324. [CrossRef] [PubMed] 
4. Kim, K.; Chun, K.H.; Suh, P.G.; Kim, I.H. Alterations in cell proliferation related gene expressions in gastric cancer. Crit. Rev. Eukaryot. Gene Expr. 2011, 21, 237-254. [CrossRef] [PubMed]

5. Feoktistova, M.; Leverkus, M. Programmed necrosis and necroptosis signalling. FEBS J. 2015, $282,19-31$. [CrossRef] [PubMed]

6. Hu, L.; Duan, Y.T.; Li, J.F.; Su, L.P.; Yan, M.; Zhu, Z.G.; Liu, B.; Yang, Q. Biglycan enhances gastric cancer invasion by activating FAK signaling pathway. Oncotarget 2014, 5, 1885-1896. [CrossRef]

7. Karl, I.; Jossberger-Werner, M.; Schmidt, N.; Horn, S.; Goebeler, M.; Leverkus, M.; Wajant, H.; Giner, T. TRAF2 inhibits TRAIL- and CD95L-induced apoptosis and necroptosis. Cell Death Dis. 2014, 5, e1444. [CrossRef]

8. Li, J.; McQuade, T.; Siemer, A.B.; Napetschnig, J.; Moriwaki, K.; Hsiao, Y.S.; Damko, E.; Moquin, D.; Walz, T.; McDermott, A.; et al. The RIP1/RIP3 necrosome forms a functional amyloid signaling complex required for programmed necrosis. Cell 2012, 150, 339-350. [CrossRef]

9. Wilson, N.S.; Dixit, V.; Ashkenazi, A. Death receptor signal transducers: Nodes of coordination in immune signaling networks. Nat. Immunol. 2009, 10, 348-355. [CrossRef]

10. Iozzo, R.V. The biology of the small leucine-rich proteoglycans. Functional network of interactive proteins. J. Biol Chem. 1999, 274, 18843-18846. [CrossRef]

11. Fisher, L.W.; Heegaard, A.M.; Vetter, U.; Vogel, W.; Just, W.; Termine, J.D.; Young, M.F. Human biglycan gene. Putative promoter, intron-exon junctions, and chromosomal localization. J. Biol. Chem. 1991, 266, 14371-14377. [PubMed]

12. Hasenohrl, R.U.; Frisch, C.; Junghans, U.; Muller, H.W.; Huston, J.P. Facilitation of learning following injection of the chondroitin sulfate proteoglycan biglycan into the vicinity of the nucleus basalis magnocellularis. Behav. Brain Res. 1995, 70, 59-67. [CrossRef]

13. Huston, J.P.; Weth, K.; De Souza Silva, A.; Junghans, U.; Muller, H.W.; Hasenohrl, R.U. Facilitation of learning and long-term ventral pallidal-cortical cholinergic activation by proteoglycan biglycan and chondroitin sulfate C. Neuroscience 2000, 100, 355-361. [CrossRef]

14. Aprile, G.; Avellini, C.; Reni, M.; Mazzer, M.; Foltran, L.; Rossi, D.; Cereda, S.; Iaiza, E.; Fasola, G.; Piga, A. Biglycan expression and clinical outcome in patients with pancreatic adenocarcinoma. Tumour. Biol. 2013, 34, 131-137. [CrossRef]

15. Williams, K.J. Arterial wall chondroitin sulfate proteoglycans: Diverse molecules with distinct roles in lipoprotein retention and atherogenesis. Curr. Opin. Lipidol. 2001, 12, 477-487. [CrossRef]

16. Mikula, M.; Rubel, T.; Karczmarski, J.; Goryca, K.; Dadlez, M.; Ostrowski, J. Integrating proteomic and transcriptomic high-throughput surveys for search of new biomarkers of colon tumors. Funct. Integr. Genomics 2011, 11, 215-224. [CrossRef]

17. Ameye, L.; Aria, D.; Jepsen, K.; Oldberg, A.; Xu, T.; Young, M.F. Abnormal collagen fibrils in tendons of biglycan/fibromodulin-deficient mice lead to gait impairment, ectopic ossification, and osteoarthritis. FASEB J. 2002, 16, 673-680. [CrossRef]

18. Nishino, R.; Honda, M.; Yamashita, T.; Takatori, H.; Minato, H.; Zen, Y.; Sasaki, M.; Takamura, H.; Horimoto, K.; Ohta, T.; et al. Identification of novel candidate tumour marker genes for intrahepatic cholangiocarcinoma. J. Hepatol. 2008, 49, 207-216. [CrossRef]

19. Pan, S.; Cheng, L.; White, J.T.; Lu, W.; Utleg, A.G.; Yan, X.; Urban, N.D.; Drescher, C.W.; Hood, L.; Lin, B. Quantitative proteomics analysis integrated with microarray data reveals that extracellular matrix proteins, catenins, and p53 binding protein 1 are important for chemotherapy response in ovarian cancers. OMICS 2009, 13, 345-354. [CrossRef]

20. Shimizu-Hirota, R.; Sasamura, H.; Kuroda, M.; Kobayashi, E.; Hayashi, M.; Saruta, T. Extracellular matrix glycoprotein biglycan enhances vascular smooth muscle cell proliferation and migration. Circ. Res. 2004, 94, 1067-1074. [CrossRef]

21. Xu, T.; Bianco, P.; Fisher, L.W.; Longenecker, G.; Smith, E.; Goldstein, S.; Bonadio, J.; Boskey, A.; Heegaard, A.M.; Sommer, B.; et al. Targeted disruption of the biglycan gene leads to an osteoporosis-like phenotype in mice. Nat. Genet. 1998, 20, 78-82. [CrossRef] [PubMed]

22. Lechner, B.E.; Lim, J.H.; Mercado, M.L.; Fallon, J.R. Developmental regulation of biglycan expression in muscle and tendon. Muscle Nerve 2006, 34, 347-355. [CrossRef] [PubMed]

23. Mercado, M.L.; Amenta, A.R.; Hagiwara, H.; Rafii, M.S.; Lechner, B.E.; Owens, R.T.; McQuillan, D.J.; Froehner, S.C.; Fallon, J.R. Biglycan regulates the expression and sarcolemmal localization of dystrobrevin, syntrophin, and nNOS. FASEB J. 2006, 20, 1724-1726. [CrossRef] [PubMed]

24. Schaefer, L.; Tredup, C.; Gubbiotti, M.A.; Iozzo, R.V. Proteolycan neofunctions: Regulation of inflammation and autophagy in cancer biology. FEBS J. 2017, 284, 10-26. [CrossRef] [PubMed] 
25. Pesic, M.; Greten, F.R. Inflammation and cancer: Tissue regeneration gone awry. Curr. Opin. Cell Biol. 2016, 43, 55-61. [CrossRef] [PubMed]

26. Van Gorp, H.; Lamkanfi, M. The emerging roles of inflammasome-dependent cytokines in cancer development. EMBO Rep. 2019, 20, e47575. [CrossRef] [PubMed]

27. Liao, L.M.; Silva, G.A.; Monteiro, M.R.; Albuquerque, S. Trypanocidal activity of quinonemethide triterpenoids from Cheiloclinium cognatum (Hippocrateaceae). Z. Naturforsch. C. 2008, 63, 207-210. [CrossRef]

28. Satoh, H. Pharmacological effectiveness of the active phytochemicals contained in foods and herbs. J. Intercult. Ethnopharmacol. 2014, 3, 196-200. [CrossRef]

29. Aragones, G.; Ardid-Ruiz, A.; Ibars, M.; Suarez, M.; Blade, C. Modulation of leptin resistance by food compounds. Mol. Nutr. Food Res. 2016, 60, 1789-1803. [CrossRef]

30. Liu, J.; Lee, J.; Salazar Hernandez, M.A.; Mazitschek, R.; Ozcan, U. Treatment of obesity with celastrol. Cell 2015, 161, 999-1011. [CrossRef]

31. Kannaiyan, R.; Manu, K.A.; Chen, L.; Li, F.; Rajendran, P.; Subramaniam, A.; Lam, P.; Kumar, A.P.; Sethi, G. Celastrol inhibits tumor cell proliferation and promotes apoptosis through the activation of c-Jun N-terminal kinase and suppression of PI3 K/Akt signaling pathways. Apoptosis 2011, 16, 1028-1041. [CrossRef] [PubMed]

32. Lee, J.S.; Yoon, I.S.; Lee, M.S.; Cha, E.Y.; Thuong, P.T.; Diep, T.T.; Kim, J.R. Anticancer activity of pristimerin in epidermal growth factor receptor 2-positive SKBR3 human breast cancer cells. Biol. Pharm. Bull. 2013, 36, $316-325$. [CrossRef] [PubMed]

33. Salminen, A.; Lehtonen, M.; Paimela, T.; Kaarniranta, K. Celastrol: Molecular targets of Thunder God Vine. Biochem. Biophys. Res. Commun. 2010, 394, 439-442. [CrossRef] [PubMed]

34. Shrivastava, S.; Jeengar, M.K.; Reddy, V.S.; Reddy, G.B.; Naidu, V.G. Anticancer effect of celastrol on human triple negative breast cancer: Possible involvement of oxidative stress, mitochondrial dysfunction, apoptosis and PI3K/Akt pathways. Exp. Mol. Pathol. 2015, 98, 313-327. [CrossRef]

35. Li, X.; Ding, J.; Li, N.; Liu, W.; Ding, F.; Zheng, H.; Ning, Y.; Wang, H.; Liu, R.; Ren, S. Synthesis and biological evaluation of celastrol derivatives as anti-ovarian cancer stem cell agents. Eur. J. Med. Chem. 2019, 179, 667-679. [CrossRef]

36. Xu, B.; Xu, M.; Tian, Y.; Yu, Q.; Zhao, Y.; Chen, X.; Mi, P.; Cao, H.; Zhang, B.; Song, G.; et al. Matrine induces RIP3-dependent necroptosis in cholangiocarcinoma cells. Cell Death Discov. 2017, 3, 16096. [CrossRef]

37. Lin, C.Y.; Chang, T.W.; Hsieh, W.H.; Hung, M.C.; Lin, I.H.; Lai, S.C.; Tzeng, Y.J. Simultaneous induction of apoptosis and necroptosis by Tanshinone IIA in human hepatocellular carcinoma HepG2 cells. Cell Death Discov. 2016, 2, 16065. [CrossRef]

38. Fu, Z.; Deng, B.; Liao, Y.; Shan, L.; Yin, F.; Wang, Z.; Zeng, H.; Zuo, D.; Hua, Y.; Cai, Z. The anti-tumor effect of shikonin on osteosarcoma by inducing RIP1 and RIP3 dependent necroptosis. BMC Cancer 2013, 13, 580. [CrossRef]

39. Lee, H.W.; Jang, K.S.; Choi, H.J.; Jo, A.; Cheong, J.H.; Chun, K.H. Celastrol inhibits gastric cancer growth by induction of apoptosis and autophagy. BMB Rep. 2014, 47, 697-702. [CrossRef]

40. Han, J.; Zhong, C.Q.; Zhang, D.W. Programmed necrosis: Backup to and competitor with apoptosis in the immune system. Nat. Immunol. 2011, 12, 1143-1149. [CrossRef]

41. Wagner, A.D.; Moehler, M. Development of targeted therapies in advanced gastric cancer: Promising exploratory steps in a new era. Curr. Opin. Oncol. 2009, 21, 381-385. [CrossRef] [PubMed]

42. Yang, H.; Ma, Y.; Chen, G.; Zhou, H.; Yamazaki, T.; Klein, C.; Pietrocola, F.; Vacchelli, E.; Souquere, S.; Sauvat, A.; et al. Contribution of RIP3 and MLKL to immunogenic cell death signaling in cancer chemotherapy. Oncoimmunology 2016, 5, e1149673. [CrossRef] [PubMed]

43. Wu, X.; Wu, M.Y.; Jiang, M.; Zhi, Q.; Bian, X.; Xu, M.D.; Gong, F.R.; Hou, J.; Tao, M.; Shou, L.M.; et al. TNF-alpha sensitizes chemotherapy and radiotherapy against breast cancer cells. Cancer Cell Int. 2017, 17, 13. [CrossRef] [PubMed]

44. Zagouri, F.; Papadimitriou, C.A.; Dimopoulos, M.A.; Pectasides, D. Molecularly targeted therapies in unresectable-metastatic gastric cancer: A systematic review. Cancer Treat. Rev. 2011, 37, 599-610. [CrossRef]

45. Yu, X.; Deng, Q.; Li, W.; Xiao, L.; Luo, X.; Liu, X.; Yang, L.; Peng, S.; Ding, Z.; Feng, T.; et al. Neoalbaconol induces cell death through necroptosis by regulating RIPK-dependent autocrine TNF-a and ROS production. Oncotarget 2015, 6, 1995-2008. [CrossRef]

46. Hsieh, L.T.; Nastase, M.V.; Zeng-Brouwers, J.; Iozzo, R.V.; Schaefer, L. Soluble biglycan as a biomarker of inflammatory renal diseases. Int. J. Biochem. Cell Biol. 2014, 54, 223-235. [CrossRef] 
47. Schaefer, L.; Babelova, A.; Kiss, E.; Hausser, H.-J.; Baliova, M.; Krzyzankova, M.; Marsche, G.; Young, M.F.; Mihalik, D.; Götte, M.; et al. The matrix component biglycan is proinflammatory and signals through toll-like receptors 4 and 2 in macrophages. J. Clin. Investig. 2005, 115, 2223-2233. [CrossRef]

48. Moreth, K.; Frey, H.; Hubo, M.; Zeng-Brouwers, J.; Nastase, M.V.; Hsieh, L.T.; Haceni, R.; Pfeilschifter, J.; Iozzo, R.V.; Schaefer, L. Biglycan-triggered TLR-2- and TLR-4-signaling exacerbates the pathophysiology of ischemic acute kidney injury. Matrix Biol. 2014, 35, 143-151. [CrossRef]

49. Moreth, K.; Brodbeck, R.; Babelova, A.; Gretz, N.; Spieker, T.; Zeng-Brouwers, J.; Pfeilschifter, J.; Young, M.F.; Schaefer, R.M.; Schaefer, L. The proteoglycan biglycan regulates expression of the B cell chemoattractant CXCL13 and aggravates murine lupus nephritis. J. Clin. Investig. 2010, 120, 4251-4272. [CrossRef]

50. Keamey, C.J.; Cullen, S.P.; Tynan, G.A.; Henry, C.M.; Clancy, D.; Lavelle, E.C.; Martin, S.J. Necroptosis suppresses inflammation via termination of TNF- or LPS-induced cytokine and chemokine production. Cell Death Differ. 2015, 22, 1313-1327.

51. Kearney, C.J.; Martin, S.J. An Inflammatory Perspective on Necroptosis. Mol. Cell 2017, 65, 965-973. [CrossRef] [PubMed]

52. Silke, J.; Rickard, J.A.; Gerlic, M. The diverse role of RIP kinases in necroptosis and inflammation. Nat. Immunol. 2015, 16, 689-697. [CrossRef] [PubMed]

53. Chen, S.J.; Guo, D.D.; Zhang, W.; Xie, Y.F.; Yang, H.J.; Cheng, B.F.; Wang, L.; Yang, R.; Bi, J.; Feng, Z. Biglycan, a Nitric Oxide-Downregulated Proteoglycan, Prevents Nitric Oxide-Induced Neuronal Cell Apoptosis via Targeting Erk1/2 and p38 Signaling Pathways. J. Mol. Neurosci. 2018, 66, 68-76. [CrossRef] [PubMed]

(C) 2019 by the authors. Licensee MDPI, Basel, Switzerland. This article is an open access article distributed under the terms and conditions of the Creative Commons Attribution (CC BY) license (http://creativecommons.org/licenses/by/4.0/). 